\title{
Avaliação físico-química e sensorial de fermentado de acerola
}

\section{Physicochemical and sensorial evaluation of a fermented West Indian cherry beverage}

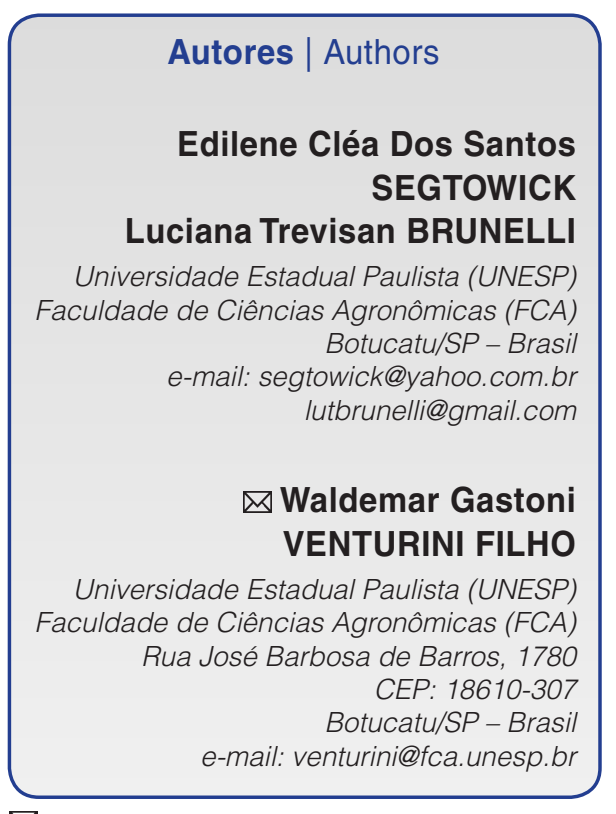

$\triangle$ Autor Correspondente / Corresponding Author

Recebido / Received: 25/06/12 Aprovado / Approved: 20/04/13 Publicado / Published: jun./2013

\section{Resumo}

O processamento de frutas para a obtenção de bebidas é uma forma de agregar valor a essa matéria-prima e remunerar melhor o produtor rural por meio do aumento de demanda. Tendo essa ideia como premissa, o objetivo deste trabalho foi produzir fermentados de acerola e caracterizá-los físico-química e sensorialmente. A produção das bebidas foi baseada na legislação brasileira de fermentado de fruta e de vinho. Os fermentados foram produzidos a partir de suco (prensa) e polpa (despolpadora) de acerola, e adoçados com açúcar para a obtenção de três tipos de bebidas: seco, meio seco e suave. As bebidas foram analisadas físico-quimicamente quanto a pH, teor alcoólico, açúcar redutor, açúcar redutor total, acidez total, acidez volátil, acidez fixa, extrato seco, extrato seco reduzido, relação álcool/extrato seco reduzido, dióxido de enxofre livre, dióxido de enxofre total e turbidez. A análise sensorial das bebidas foi feita pelo teste de escala hedônica estruturada de nove pontos, sendo considerados aparência, odor, sabor e avaliação global. Os resultados das análises físico-químicas e sensorial foram submetidos à análise de variância e as médias foram comparadas pelo teste de Tukey (significância de 5 \%). Tanto as matérias-primas (suco e polpa) como as diferentes concentrações de açúcar (seco, semisseco e suave) interferiram nos parâmetros físico-químicos e sensoriais dos fermentados de acerola, sendo que os provadores demonstraram preferência pelas bebidas mais adocicadas.

Palavras-chave: Malpighia glabra L.; Bebida fermentada; Análise sensorial; Análise físico-química.

\section{Summary}

Fruit processing for beverage production purposes is a way of adding value to the raw material and of raising the farmer's income by increasing the demand. Thus the objective of this work was the production of fermented West Indian cherry beverages and their physicochemical and sensory evaluation. The beverages were produced based on the Brazilian legislation for fermented fruit beverages and wine. The fermented beverages were produced from West Indian cherry pulp (pulper) and juice (press) and sweetened with sugar to obtain three types of beverage: dry, semidry and sweet. The beverages were submitted to the following physicochemical analyses: $\mathrm{pH}$, alcohol, reducing sugars, total reducing sugars, total acidity, volatile acidity, fixed acidity, dry extract, reduced dry extract, alcohol to reduced dry extract ratio, free sulphur dioxide, total sulphur dioxide and turbidity. In the sensory analysis, the beverages were assessed using a 9-point hedonic scale, evaluating the attributes of appearance, odour, flavour and overall assessment. The chemical and sensory results were submitted to an analysis of variance and the means compared using Tukey's test (5\%). Both the raw materials (pulp and juice) and the different sugar concentrations (dry, semidry and sweet) interfered in the sensory and physicochemical parameters of the fermented West Indian cherry beverages, the tasters showing preference for the sweetened beverages.

Key words: Malpighia glabra L.; Fermented beverage; Sensory analysis; Chemical analysis. 


\section{Introdução}

No mercado brasileiro, a acerola é comercializada in natura, congelada, na forma de polpa congelada, néctar, suco tropical, suco concentrado, licor, etc. É usada ainda no enriquecimento de sucos e néctares de outras frutas. Outros produtos de acerola que podem ser encontrados no mercado brasileiro são acerola em pó, cápsulas medicinais de vitamina $\mathrm{E}$ e $\mathrm{C}$, geleias e doces (MANICA et al., 2003).

Uma das formas de agregar valor à produção de acerola é processá-la para a produção de bebidas alcoólicas e não alcoólicas. A partir desta constatação, a Associação Agrícola de Junqueirópolis, município do Estado de São Paulo, apoiou a presente pesquisa para a elaboração de um fermentado de acerola, visando a oferecer aos produtores da região uma alternativa de aproveitamento tecnológico dessa fruta.

Segundo o Ministério da Agricultura Pecuária e Abastecimento, fermentado de fruta é a bebida com graduação alcoólica de 4 a $14 \%$ em volume, a $20{ }^{\circ} \mathrm{C}$, obtida da fermentação alcoólica do mosto de fruta sã, fresca e madura (BRASIL, 2009).

No Brasil, estudos sobre a produção de fermentado de acerola foram realizados no Estado do Sergipe. Santos et al. (2005) trabalharam com mosto obtido a partir de polpa de acerola. A bebida apresentou cor, aroma e sabor característicos dos frutos da acerola, com graduação alcoólica e todas as outras características físico-químicas dentro das normas brasileiras. A análise sensorial (escala hedônica) mostrou que a aceitabilidade do fermentado de acerola foi semelhante à do vinho de uva comercial, sendo que as médias dos atributos aparência, aroma e sabor ficaram entre 6 e 7 .

Evangelista et al. (2005) produziram fermentados a partir de polpa de acerola. As bebidas apresentaram coloração levemente avermelhada, aroma característico da acerola e sabor adocicado. $\mathrm{Na}$ análise sensorial (escala hedônica), as médias de notas para os atributos aparência, sabor e aroma ficaram próximas de 6. De acordo com os autores, os parâmetros físico-químicos ficaram em conformidade com a legislação brasileira.

Os dois autores citados anteriormente elaboraram fermentados alcoólicos a partir de polpa de acerola. $\mathrm{Na}$ presente pesquisa, o uso da polpa e do suco justifica-se pelo fato de essas matérias-primas poderem alterar as características físico-químicas e sensoriais da bebida. Além disso, a forma de extração (despolpadora/prensa) pode determinar diferentes rendimentos de polpa ou suco, com reflexos na economicidade do processo de produção de fermentados.

O objetivo deste trabalho foi produzir fermentados de acerola dos tipos seco, semisseco e suave, a partir de suco e polpa, bem como caracterizá-los físico-química e sensorialmente.

\section{Material e métodos}

\subsection{Planejamento experimental}

O delineamento experimental da produção de fermentado de acerola foi inteiramente casualizado, no arranjo fatorial $2 \times 3$, combinação de duas matériasprimas (suco e polpa) e três tipos de bebidas (seco, semisseco e suave). O ensaio foi planejado com seis tratamentos e três repetições, perfazendo 18 parcelas experimentais, conforme descrito a seguir:

- $T_{1}$ - fermentado seco (5 g de glicose $\mathrm{L}^{-1}$ ) de polpa de acerola;

- $\mathrm{T}_{2}$ - fermentado semisseco (19 g de glicose $\mathrm{L}^{-1}$ ) de polpa de acerola;

- $\mathrm{T}_{3}$ - fermentado suave (75 g de glicose $\mathrm{L}^{-1}$ ) de polpa de acerola;

- $\mathrm{T}_{4}$ - fermentado seco (5 g de glicose $\mathrm{L}^{-1}$ ) de suco de acerola;

- $\mathrm{T}_{5}$ - fermentado semisseco (19 $\mathrm{g}$ de glicose $\mathrm{L}^{-1}$ ) de suco de acerola;

- $\mathrm{T}_{6}$ - fermentado suave (75 g de glicose $\mathrm{L}^{-1}$ ) de suco de acerola.

Para os ensaios de extração de polpa e suco, foi utilizado o delineamento inteiramente casualizado, com dois tratamentos e três repetições, perfazendo seis parcelas experimentais.

\subsection{Processamento do fermentado}

A acerola in natura da variedade Olivier foi fornecida pela Associação Agrícola de Junqueirópolis, SP. As frutas foram selecionadas visualmente (eliminaram-se os frutos deteriorados e verdes, folhas, galhos e insetos) e lavadas com água corrente.

A extração da polpa foi realizada em despolpadora vertical (MECAMAU D-003) com peneira de 0,5 mm. A despolpadora foi carregada com $5 \mathrm{~kg}$ de acerola por carga e mantida em funcionamento por 4 minutos. A extração do suco foi realizada em prensa hidráulica munida de cesto perfurado ( $3 \mathrm{~mm}$ ) e tecido sintético (voil), para acondicionamento dos frutos, com malha aproximada de 0,1 mm. A prensa foi carregada com 1,5 kg de acerola por carga e a pressão de trabalho foi de

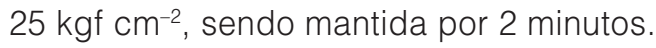

Após a extração, foi calculado o rendimento de obtenção da polpa e do suco por meio da Equação 1:

$\mathrm{R}=\frac{\mathrm{m}}{\mathrm{M}} \times 100$

em que: $R=$ rendimento; $m$ = massa de polpa ou massa de suco; $M$ = massa de acerola. 
Para a obtenção do mosto proveniente de suco, este foi corrigido de 7,9 para $20^{\circ}$ Brix com xarope de açúcar cristal $\left(47,7^{\circ}\right.$ Brix). No caso do mosto feito a partir de polpa, esta foi diluída com água (1:1) e depois corrigida de 4,6 para $20^{\circ}$ Brix com xarope de açúcar cristal $\left(61,1^{\circ} \mathrm{Brix}\right)$. As correções foram feitas a partir de balanço de massa, conforme a Equação 2:

$$
B_{1} \times M_{1}+B_{2} \times M_{2}=B_{3} \times M_{3}
$$

em que: $B_{1}=$ Brix do suco ou polpa de acerola; $M_{1}=$ Massa do suco ou polpa de acerola; $B_{2}=$ Brix do xarope; $\mathrm{M}_{2}=$ Massa do xarope; $\mathrm{B}_{3}=$ Brix do mosto de suco ou polpa; $\mathrm{M}_{3}=$ Massa do mosto de suco ou polpa.

A inoculação foi realizada com levedura seca selecionada CA-11, fornecida pela Empresa LNF Latino Americana, na concentração de $6 \mathrm{~g} \mathrm{~L}^{-1}$. A levedura foi suspensa em $1 \mathrm{~L}$ de mosto a $35^{\circ} \mathrm{C}$ e depois misturada ao restante do mosto, sob agitação por 1 minuto. Em seguida, o mosto foi transferido para os fermentadores de aço inoxidável com capacidade de $50 \mathrm{~L}$ e deixado fermentar na temperatura ambiente. A fermentação foi verificada diariamente até a estabilização do Brix.

Ao final da fermentação, realizou-se a descuba, separando-se o fermentado da borra decantada (levedura e sólidos insolúveis). Cada fermentado foi transferido para garrafões de vidro $(4,5 \mathrm{~L})$, por meio de uma bomba peristáltica. A borra decantada foi centrifugada e o sobrenadante adicionado ao fermentado. Nos garrafões, foi realizado o atesto com a adição de nitrogênio líquido para expulsar o ar de seu interior. Em seguida, os garrafões foram fechados com batoques hidráulicos. Os fermentados foram deixados em repouso por 30 dias.

Em seguida, foi realizada a primeira trasfega, sendo que os fermentados permaneceram em repouso por mais 30 dias, para a separação da borra. $\mathrm{Na}$ segunda trasfega, foi feita a clarificação da bebida com bentonita $\left(0,4 \mathrm{~g} \mathrm{~L}^{-1}\right)$. Depois de 15 dias, realizou-se a terceira trasfega, a adição de açúcar cristal prevista nos tratamentos, bem como a sulfitação. Esta foi realizada com a adição de $80 \mathrm{mg} \mathrm{L}^{-1}$ de metabissulfito de potássio aos fermentados secos. Para os fermentados semissecos e suaves, foram adicionados $100 \mathrm{mg} \mathrm{L}^{-1}$ de metabissulfito de potássio, juntamente com $150 \mathrm{mg} \mathrm{L}^{-1}$ de ácido sórbico. Os conservantes foram dissolvidos no próprio fermentado. Posteriormente, foi realizado o engarrafamento dos fermentados em garrafas de vidro verde, com capacidade para $750 \mathrm{~mL}$. As garrafas foram fechadas com rolha de cortiça.

\subsection{Análises físico-químicas}

A polpa e o suco foram analisados quanto aos seguintes aspectos: teor de sólidos solúveis (densímetro digital marca Mettler e uso de tabela de conversão densidade/Brix); pH (pHmetro marca Micronal); sólidos insolúveis (BRASIL, 2005); açúcar redutor e açúcar redutor total, por titulometria do licor de Fehling, conforme o método de Lane-Eynon descrito por Copersucar (2001).

Nos fermentados, foram analisados $\mathrm{pH}$, acidez total, volátil e fixa (BRASIL, 2005), teor alcoólico (método da destilação com uso de densímetro digital e tabela de conversão densidade/teor alcoólico), açúcar redutor e açúcar redutor total por titulometria do licor de Fehling, conforme o método de Lane-Eynon descrito por Copersucar (2001), extrato seco, extrato seco reduzido, relação álcool/extrato seco reduzido, dióxido de enxofre e dióxido de enxofre total (CATALUÑA, 1991), e turbidez (turbidímetro marca Hach).

\subsection{Análise sensorial}

Os fermentados foram analisados sensorialmente por meio de teste afetivo - teste de aceitação de escala hedônica estruturada de nove pontos, ancorada pelas notas de 1 (desgostei extremamente) a nota 9 (gostei extremamente) (BEHRENS, 2011). Foram avaliados os seguintes atributos: aparência, odor, sabor e avaliação global. Para cada provador, foram oferecidas três amostras (seco, semisseco, suave) de fermentados, elaborados com polpa ou suco, e água potável. As amostras foram servidas em taças de vidro contendo $20 \mathrm{~mL}$ da bebida. Os testes foram conduzidos com balanceamento de amostras, sob luz branca. Foi utilizado um painel com 50 provadores não selecionados e não treinados, de ambos os gêneros.

\subsection{Análise estatística}

Os resultados das análises físico-químicas das matérias-primas (polpa e suco) foram submetidos à análise de variância (ANOVA) e as médias comparadas pelo teste $\mathrm{t}$ ( $5 \%$ de probabilidade). Os resultados das análises físico-químicas e sensoriais dos fermentados foram submetidos à análise de variância e as médias foram comparadas pelo teste de Tukey com significância de $5 \%$ de probabilidade (VIEIRA, 2006), com o auxílio do software estatístico ASSISTAT (SILVA e AZEVEDO, 2009).

\section{Resultados e discussão}

A Tabela 1 mostra os resultados das análises físico-químicas da polpa e do suco de acerola utilizados

Tabela 1. Característica físico-química de polpa de acerola extraída em despolpadora e de suco de acerola extraído em prensa.

\begin{tabular}{lcc}
\multicolumn{1}{c}{ Análise } & Polpa & Suco \\
\hline pH & $3,49 \pm 0,07^{\mathrm{a}}$ & $3,26 \pm 0,12^{\mathrm{b}}$ \\
Acidez Total (ác. cítrico) & $1,06 \pm 0,07^{\mathrm{a}}$ & $1,07 \pm 0,08^{\mathrm{a}}$ \\
Sólidos Solúveis ( $\left.{ }^{\circ} \mathrm{Brix}\right)$ & $9,45 \pm 0,05^{\mathrm{a}}$ & $8,28 \pm 0,19^{\mathrm{b}}$ \\
Sólidos Insolúveis (\%) & $4,30 \pm 0,14^{\mathrm{a}}$ & $0,80 \pm 0,06^{\mathrm{b}}$ \\
\hline
\end{tabular}

Médias seguidas pela mesma letra não diferem significativamente entre si, a $5 \%$ de probabilidade, pelo teste t. 
na produção dos fermentados. Exceção feita à acidez total, todos os demais parâmetros analisados foram influenciados pelo tipo de matéria-prima. Esses dados estão em concordância com os obtidos por Caetano et al. (2012), que trabalharam com polpa e suco de acerola da região de Junqueirópolis, e com os de Brunini et al. (2004), que caracterizaram físico-quimicamente acerolas provenientes de diferentes regiões do Estado de São Paulo e verificaram que o $\mathrm{pH}$ variou de 2,39 a 4,00, os valores de acidez, de 0,50 a 1,11\%, e os teores de sólidos solúveis, de 5,67 a 8,22 ${ }^{\circ}$ Brix.

A polpa apresentou maior teor de sólidos insolúveis em relação ao suco. Sua maior riqueza em sólidos insolúveis ocorre em função do tipo de extração. A despolpadora promove a desintegração dos tecidos da fruta, cujos fragmentos são incorporados ao produto, enquanto que, na prensagem, os tecidos vegetais não se fragmentam, atuando como elemento filtrante do suco; além disso, o tecido sintético de malha fina (voil) atua como barreira à passagem de partículas insolúveis.

A polpa também apresentou maior concentração de sólidos solúveis em relação ao suco. Na medida em que a leitura de Brix foi feita com amostras clarificadas por centrifugação (4500 rpm/5 minutos), essa diferença não pode ser creditada à presença de sólidos insolúveis na amostra. A diferença decorre do tipo de extração, sendo provável que componentes celulares resultantes do despolpamento tenham enriquecido a polpa em sólidos solúveis e substâncias coloidais, alterando a leitura de Brix.

Apesar de a acidez total ser a mesma para ambas as matérias-primas, o valor de $\mathrm{pH}$ da polpa foi superior ao do suco. Este resultado pode ser um indicativo de que a polpa apresente maior poder tampão em relação ao suco.

O processamento da acerola em despolpadora gerou um rendimento de polpa de $77 \%$, enquanto que, na prensa, este valor foi de $65 \%$ de suco. O maior rendimento apresentado pela despolpadora foi devido à extração de suco e, concomitantemente, de sólidos insolúveis (fragmentos de tecidos do fruto), ao passo que a prensa extraiu suco praticamente isento de sólidos em suspensão. O maior rendimento de extração de polpa poderia resultar em uma maior produção de fermentado, entretanto esse tipo de matéria-prima gera maior quantidade de borra durante as operações de trasfegas, podendo anular essa vantagem.

A Tabela 2 mostra o resultado da ANOVA (teste F) das análises físico-químicas dos diferentes tipos de fermentados (seco, semisseco e suave), fabricados com polpa e suco de acerola.

Os tratamentos (matérias-primas e tipo de bebida) interferiram nos parâmetros físicos e químicos de todas as bebidas, exceção feita à turbidez, que não sofreu influência das matérias-primas.

Os fermentados suaves apresentaram os maiores valores de $\mathrm{pH}$ e menores de acidez (Tabela 3). A adição de açúcar nas bebidas reduz a concentração de todos os seus componentes solúveis, entre os quais os ácidos orgânicos e os prótons destes dissociados. O tipo de matéria-prima não interferiu no pH das bebidas.

Os fermentados elaborados com suco apresentaram teores de acidez total e fixa mais elevados em relação aos fermentados de polpa. Isto ocorreu em função da diluição da polpa com água (1:1) durante o preparo das bebidas. A acidez total dos fermentados de polpa e do fermentado suave de suco permaneceram dentro do limite determinado pela legislação brasileira para vinho de mesa, que estabelece limites entre 55,0 e 130,0 meq $\mathrm{L}^{-1}$ (BRASIL, 1988); as demais bebidas de suco ficaram acima do estabelecido pela legislação.

Tabela 2. Significâncias estatísticas obtidas pelo teste $\mathrm{F}$ para as análises físico-químicas realizadas nos fermentados de acerola.

\begin{tabular}{|c|c|c|c|}
\hline Parâmetros & $\begin{array}{l}\text { Matéria-prima } \\
\text { (polpa e suco) }\end{array}$ & $\begin{array}{c}\text { Tipo de bebida } \\
\text { (seco, semisseco e suave) }\end{array}$ & $\begin{array}{c}\text { Interação } \\
\text { matéria-prima } \times \text { tipo de bebida }\end{array}$ \\
\hline $\mathrm{pH}$ & ** & ** & $\star \star *$ \\
\hline Acidez total (meq L-1) & ** & ** & ** \\
\hline Acidez volátil (meq L-1) & ** & ** & ns \\
\hline Acidez fixa (meq $\left.L^{-1}\right)$ & ** & ** & ** \\
\hline Teor alcoólico (\% v/v) & ** & ** & * \\
\hline Açúcar redutor (g glicose 100 mL-1) & ** & ** & ** \\
\hline Açúcar redutor total (g glicose $100 \mathrm{~mL}^{-1}$ ) & ** & ** & ** \\
\hline Extrato seco $\left(\mathrm{g} \mathrm{L}^{-1}\right)$ & ** & ** & ns \\
\hline Extrato seco reduzido $\left(g \mathrm{~L}^{-1}\right)$ & ** & ** & ns \\
\hline Relação teor alcoólico/extrato seco reduzido & ** & ** & ** \\
\hline $\mathrm{SO}_{2}$ Livre $\left(\mathrm{mg} \mathrm{L}^{-1}\right)$ & * & ** & ns \\
\hline $\mathrm{SO}_{2}$ Total $\left(\mathrm{mg} \mathrm{L}^{-1}\right)$ & * & ** & ns \\
\hline Turbidez (NTU) & ns & ** & ns \\
\hline
\end{tabular}

**significativo no nível de $1 \%$ de probabilidade $(p<0,01)$; *significativo no nível de $5 \%$ de probabilidade $(p<0,05)$; ns: não significativo $(p \geq 0,05)$. 
Avaliação físico-química e sensorial de fermentado de acerola

SEGTOWICK, E. C. S. et al.

Tabela 3. Caracterização físico-química dos fermentados de acerola.

\begin{tabular}{|c|c|c|c|c|}
\hline \multicolumn{4}{|c|}{ Tipos de bebidas } & Média \\
\hline \multicolumn{5}{|c|}{$\mathrm{pH}$} \\
\hline Polpa & $3,56 \pm 0,03^{a c}$ & $3,58 \pm 0,01^{a B}$ & $3,63 \pm 0,01^{\mathrm{aA}}$ & $3,59 \pm 0,03^{a}$ \\
\hline Suco & $3,56 \pm 0,01^{a c}$ & $3,58 \pm 0,02^{a B}$ & $3,60 \pm 0,01^{a A}$ & $3,58 \pm 0,02^{a}$ \\
\hline Média & $3,56 \pm 0,01^{c}$ & $3,58 \pm 0,01^{b}$ & $3,61 \pm 0,01^{a}$ & \\
\hline \multicolumn{5}{|c|}{ Acidez Total (meq $L^{-1}$ ) } \\
\hline Polpa & $98,78 \pm 0,44^{\mathrm{bB}}$ & $100,44 \pm 0,88^{\mathrm{bA}}$ & $97,56 \pm 1,59^{\mathrm{bC}}$ & $98,93 \pm 1,59^{b}$ \\
\hline Suco & $135,33 \pm 0,50^{\mathrm{aA}}$ & $135,89 \pm 0,78^{a A}$ & $128,78 \pm 1,39^{\mathrm{aB}}$ & $133,33 \pm 3,42^{a}$ \\
\hline Média & $117,06 \pm 8,81^{a}$ & $118,17 \pm 8,25^{a}$ & $113,17 \pm 6,13^{b}$ & \\
\hline \multicolumn{5}{|c|}{ Acidez Volátil (meq $L^{-1}$ ) } \\
\hline Polpa & $4,00 \pm 0,50$ & $4,22 \pm 0,67$ & $3,50 \pm 0,66$ & $3,91 \pm 0,67^{b}$ \\
\hline Suco & $4,89 \pm 0,74$ & $5,22 \pm 0,79$ & $3,94 \pm 0,81$ & $4,68 \pm 0,93^{a}$ \\
\hline Média & $4,45 \pm 0,76^{a}$ & $4,71 \pm 0,88^{a}$ & $3,71 \pm 0,75^{b}$ & \\
\hline \multicolumn{5}{|c|}{ Acidez Fixa (meq L-1) } \\
\hline Polpa & $93,78 \pm 0,44^{\mathrm{bB}}$ & $96,22 \pm 1,06^{\mathrm{bA}}$ & $94,06 \pm 1,65^{\mathrm{bB}}$ & $95,02 \pm 1,45^{b}$ \\
\hline Suco & $130,44 \pm 0,92^{\mathrm{aA}}$ & $130,67 \pm 0,92^{\mathrm{aA}}$ & $124,83 \pm 1,54^{\mathrm{aB}}$ & $128,65 \pm 2,99^{a}$ \\
\hline Média & $112,61 \pm 8,36^{a}$ & $113,44 \pm 7,75^{\mathrm{a}}$ & $109,44 \pm 5,91^{b}$ & \\
\hline \multicolumn{5}{|c|}{ Teor Alcoólico (\% v/v) } \\
\hline Polpa & $11,09 \pm 0,20^{\mathrm{aA}}$ & $10,71 \pm 0,43^{a \mathrm{~B}}$ & $10,40 \pm 0,24^{\mathrm{aB}}$ & $10,73 \pm 0,41^{\mathrm{a}}$ \\
\hline Suco & $10,47 \pm 0,19^{\mathrm{bA}}$ & $10,69 \pm 0,31^{\mathrm{aA}}$ & $9,77 \pm 0,36^{\mathrm{bB}}$ & $10,28 \pm 0,47^{b}$ \\
\hline Média & $10,78 \pm 0,37^{a}$ & $10,66 \pm 0,37^{a}$ & $10,07 \pm 0,44^{b}$ & \\
\hline \multicolumn{5}{|c|}{ Açúcar Redutor (g glicose $100 \mathrm{~mL}^{-1}$ ) } \\
\hline Polpa & $0,47 \pm 0,02^{b c}$ & $1,80 \pm 0,01^{\mathrm{bB}}$ & $5,68 \pm 0,07^{\mathrm{aA}}$ & $2,65 \pm 0,25^{b}$ \\
\hline Suco & $0,59 \pm 0,01^{\mathrm{ac}}$ & $1,89 \pm 0,02^{\mathrm{aB}}$ & $5,68 \pm 0,07^{\mathrm{aA}}$ & $2,72 \pm 0,20^{a}$ \\
\hline Média & $0,53 \pm 0,06 c$ & $1,84 \pm 0,05^{b}$ & $5,68 \pm 0,07^{a}$ & \\
\hline \multicolumn{5}{|c|}{ Açúcar Redutor Total (g glicose $100 \mathrm{~mL}^{-1}$ ) } \\
\hline Polpa & $0,49 \pm 0,02^{b c}$ & $1,98 \pm 0,01^{\mathrm{aB}}$ & $7,68 \pm 0,04^{\mathrm{bA}}$ & $3,38 \pm 0,16^{b}$ \\
\hline Suco & $0,52 \pm 0,01^{\mathrm{ac}}$ & $1,96 \pm 0,02^{\mathrm{aB}}$ & $7,78 \pm 0,05^{\mathrm{aA}}$ & $3,42 \pm 0,23^{a}$ \\
\hline Média & $0,51 \pm 0,03^{c}$ & $1,97 \pm 0,02^{b}$ & $7,73 \pm 0,07^{a}$ & \\
\hline \multicolumn{5}{|c|}{ Extrato Seco $\left(g \mathrm{~L}^{-1}\right)$} \\
\hline Polpa & $23,08 \pm 0,65$ & $37,50 \pm 1,58$ & $90,30 \pm 0,86$ & $50,29 \pm 0,57^{b}$ \\
\hline Suco & $29,72 \pm 0,73$ & $45,25 \pm 1,83$ & $97,79 \pm 0,10$ & $57,58 \pm 0,73^{a}$ \\
\hline Média & $26,40 \pm 3,48^{c}$ & $41,37 \pm 4,56^{b}$ & $94,04 \pm 3,90^{a}$ & \\
\hline \multicolumn{5}{|c|}{ Extrato Seco Reduzido (g L-1) } \\
\hline Polpa & $19,21 \pm 0,68$ & $18,67 \pm 1,58$ & $14,48 \pm 1,13$ & $17,45 \pm 2,44^{b}$ \\
\hline Suco & $25,47 \pm 0,77$ & $26,60 \pm 2,71$ & $20,95 \pm 0,51$ & $24,34 \pm 2,95^{a}$ \\
\hline Média & $22,34 \pm 3,30^{a}$ & $22,64 \pm 4,61^{a}$ & $17,72 \pm 3,44^{b}$ & \\
\hline & & TA/ESR & & \\
\hline Polpa & $4,63 \pm 0,20^{\mathrm{aB}}$ & $4,63 \pm 0,48^{\mathrm{aB}}$ & $5,78 \pm 0,52^{\mathrm{aA}}$ & $5,01 \pm 0,69 a$ \\
\hline Suco & $3,29 \pm 012^{\mathrm{bB}}$ & $3,21 \pm 0,25^{\mathrm{bB}}$ & $3,73 \pm 0,15^{\mathrm{bA}}$ & $3,41 \pm 0,29^{b}$ \\
\hline Média & $3,96 \pm 0,71^{b}$ & $3,92 \pm 0,82^{b}$ & $4,75 \pm 1,12^{\mathrm{a}}$ & \\
\hline \multicolumn{5}{|c|}{$\mathrm{SO}_{2}$ Livre $\left(\mathrm{mg} \mathrm{L}^{-1}\right)$} \\
\hline Polpa & $42,74 \pm 4,11$ & $54,01 \pm 4,75$ & $54,93 \pm 5,19$ & $50,56 \pm 2,23^{b}$ \\
\hline Suco & $45,11 \pm 2,71$ & $56,78 \pm 3,93$ & $58,11 \pm 3,59$ & $53,33 \pm 1,81^{a}$ \\
\hline Média & $43,93 \pm 3,59^{b}$ & $55,39 \pm 4,46^{a}$ & $56,52 \pm 3,66^{a}$ & \\
\hline \multicolumn{5}{|c|}{$\mathrm{SO}_{2}$ Total $\left(\mathrm{mg} \mathrm{L}^{-1}\right)$} \\
\hline Polpa & $61,57 \pm 1,88$ & $76,56 \pm 3,28$ & $72,76 \pm 6,50$ & $70,29 \pm 7,71^{a}$ \\
\hline Suco & $68,11 \pm 3,14$ & $75,67 \pm 2,92$ & $69,31 \pm 3,80$ & $71,03 \pm 4,64^{a}$ \\
\hline Média & $64,81 \pm 4,20^{\circ}$ & $76,11 \pm 3,05^{a}$ & $71,03 \pm 5,46^{b}$ & \\
\hline \multicolumn{5}{|c|}{ Turbidez (NTU) } \\
\hline Polpa & $8,21 \pm 0,79$ & $10,22 \pm 0,54$ & $16,24 \pm 0,28$ & $11,56 \pm 3,52$ \\
\hline Suco & $8,58 \pm 0,52$ & $10,26 \pm 0,49$ & $16,07 \pm 0,29$ & $11,64 \pm 3,29$ \\
\hline Média & $8,40 \pm 0,60^{\circ}$ & $10,24 \pm 0,50^{b}$ & $16,16 \pm 0,29^{a}$ & \\
\hline
\end{tabular}

Médias seguidas pela mesma letra minúscula entre colunas e maiúscula entre linhas não diferem significativamente entre si, a 5 \% de probabilidade, pelo teste de Tukey. 
Os baixos valores de acidez volátil encontrados nos fermentados mostram que a polpa e o suco encontravam-se em bom estado de sanidade e que as bebidas foram tecnologicamente bem elaboradas. O teor de acidez volátil deve ser o mais baixo possível. Teores elevados indicam alterações microbiológicas nos vinhos (HASHIZUME, 2001). Os valores de acidez volátil dos fermentados encontram-se dentro do padrão estabelecido pela legislação brasileira para vinho de mesa, que indica o valor máximo de 20 meq L-1 (BRASIL, 1988).

Embora os mostos tivessem o mesmo Brix inicial (20 Brix), os fermentados apresentaram diferentes teores alcoólicos (Tabela 3). O teor alcoólico do fermentado de polpa $(10,73 \% \mathrm{v} / \mathrm{v})$ foi maior em relação ao fermentado de suco $(10,28 \%$ v/v). O mosto do fermentado elaborado a partir da polpa, durante seu preparo, foi inicialmente diluído com água (1:1) e depois teve seu teor de sólidos solúveis corrigido com xarope de sacarose, proporcionando maior pureza (açúcar/Brix) e maior fermentabilidade (álcool/Brix) ao mosto de polpa.

A adição de açúcar nos diferentes tipos de bebidas (seco, semisseco e suave) também alterou seu teor alcoólico. Neste caso, o açúcar adicionado antes do engarrafamento diluiu todos os demais componentes químicos das bebidas, inclusive o álcool. Os valores de teor alcoólico encontrados no presente trabalho (10,07 a $10,78 \%$ v/v) estão próximos dos valores $\left(11^{\circ} \mathrm{GL}\right)$ publicados por Santos et al. (2005) e Evangelista et al. (2005), que trabalharam com mosto a $24^{\circ}$ Brix. O teor alcoólico das bebidas manteve-se dentro do limite estabelecido pela legislação brasileira (BRASIL, 2009) para fermentado de fruta (4 a $\left.14^{\circ} \mathrm{GL}\right)$.

Os teores de açúcar redutor e açúcar redutor total estão em conformidade com os tipos de bebidas propostos, aumentando do seco para o suave (Tabela 3). Os valores próximos de AR e ART, para um mesmo tratamento, indicam a hidrólise da sacarose usada no seu adoçamento, sendo que esta foi mais efetiva nas bebidas secas e semissecas. A hidrólise da sacarose foi favorecida pelo $\mathrm{pH}$ baixo das bebidas $(3,6)$, conforme previsto por Ribeiro e Seravalli (2004). Os fermentados elaborados com polpa apresentaram os menores teores de AR e ART em função da maior pureza e da fermentabilidade de seus mostos. A legislação brasileira para vinhos de mesa estabelece teores de glicose abaixo de $5 \mathrm{~g} \mathrm{~L}^{-1}$ para vinhos secos; acima de $5 \mathrm{~g} \mathrm{~L}^{-1}$ até $20 \mathrm{~g} \mathrm{~L}^{-1}$ para semissecos, e acima de $20 \mathrm{~g} \mathrm{~L}^{-1}$ para vinhos suaves (BRASIL, 1988). Os resultados de ART dos fermentados, demonstram que a adição de açúcar aos fermentados foi apropriada, resultando na adequação de todos os fermentados à legislação.

O extrato seco é composto por ácidos fixos, sais orgânicos, sais minerais, polialcoóis, compostos fenólicos, compostos nitrogenados, açúcares e polissacarídeos
(RIZZON e MIELE, 1996). Os resultados de extrato seco (Tabela 3) foram maiores para os fermentados de suco, em função do efeito da diluição da polpa no preparo do mosto, que promoveu a diminuição dos sólidos solúveis não fermentáveis. Entre os fermentados de mesma matéria-prima, observou-se um aumento crescente do extrato seco em função da adição de açúcar nas bebidas (seco, semisseco, suave). A legislação brasileira de vinho não estabelece valores para extrato seco nem para extrato seco reduzido. Hashizume (2001) afirmou que o teor de extrato determina o corpo do vinho e que bebidas com menos de $20 \mathrm{~g} \mathrm{~L}^{-1}$ de extrato são consideradas leves e, acima de $25 \mathrm{~g} \mathrm{~L}^{-1}$, encorpadas. Dessa forma, os fermentados de acerola com maior concentração de açúcar (extrato seco) poderão ser percebidos sensorialmente como bebidas mais encorpadas.

A relação álcool/extrato seco reduzido representa o equilíbrio entre os constituintes voláteis e os fixos do vinho (RIZZON e MIELE, 1996). Esta relação é um parâmetro para detecção de fraudes nessa bebida. De acordo com a legislação brasileira, o limite máximo é de 4,8 para vinhos tintos, de 6,0 para vinhos rosados e 6,5 para vinhos brancos (BRASIL, 1988). Assim, os fermentados obtidos a partir de polpa de acerola apresentaram relação álcool/ extrato seco reduzido abaixo do limite máximo permitido para vinhos rosados, enquanto aqueles produzidos a partir de suco ficaram abaixo do limite máximo para vinho tinto.

Os fermentados com maior concentração de açúcar (semisseco e suave) apresentaram maiores teores de dióxido de enxofre livre e total em função da sulfitação realizada na elaboração dessas bebidas; as bebidas secas receberam menor dose de enxofre. Quanto ao dióxido de enxofre total, verificou-se que todas as amostras se encontraram abaixo dos valores estipulados por lei para o vinho de mesa, ou seja, abaixo de $350 \mathrm{mg}$ $\mathrm{L}^{-1}$ (BRASIL, 1988). Não há valores estabelecidos por lei quanto ao dióxido de enxofre livre.

A turbidez foi proporcional à concentração de açúcar nas bebidas e não foi alterada pela matéria-prima empregada na sua formulação (Tabela 3). Os sólidos insolúveis da polpa de acerola, que poderiam causar elevação de turbidez na bebida final, foram removidos durante as operações de clarificação (bentonita) e trasfegas. Entretanto, o açúcar cristal empregado para adoçar os fermentados (semisseco e suave) carrega consigo, segundo Oliveira (2006), partículas de tamanho coloidal (amido, gomas, compostos de cor, fibras de bagaço, partículas metálicas, etc.) que podem turvar as bebidas, como aconteceu no presente trabalho.

A matéria-prima e o teor de açúcar influenciaram os atributos sensoriais dos fermentados de acerola, conforme os resultados da análise de variância mostrados na Tabela 4. Apesar disso, o teste de Tukey (Tabela 5) não 
Avaliação físico-química e sensorial de fermentado de acerola

SEGTOWICK, E. C. S. et al.

foi significativo para todos os tratamentos, exceto para os atributos sabor e avaliação global dos fermentados secos, semissecos e suaves.

Embora a adição de açúcar cristal tenha promovido o aumento na turbidez das bebidas suaves (mensurada em turbidímetro), os provadores não foram capazes de perceber visualmente essa alteração (Tabela 4 e Figura 1).

Em relação ao atributo odor, os provadores não perceberam qualquer variação em função do tipo de matéria-prima. Belitz et al. (2009) relataram que o teor de açúcar de uma solução (bebida) está correlacionado com a avaliação sensorial dos compostos voláteis de aroma, ou seja, a presença de açúcar deve interferir na percepção sensorial dos aromas das bebidas, mas isso não foi verificado pelo painel sensorial do presente trabalho.

Os provadores preferiram os fermentados adocicados, cujas médias para o atributo sabor ficaram acima de 7 (gostei regularmente), independentemente do tipo de matéria-prima usada na sua fabricação. As bebidas suaves apresentaram médias de sabor acima dos valores publicados por Evangelista et al. (2005) e Santos et al. (2005), que produziram fermentados de acerola em condições semelhantes. Porém, as bebidas secas foram mais mal avaliadas em relação aos fermentados elaborados por esses autores.

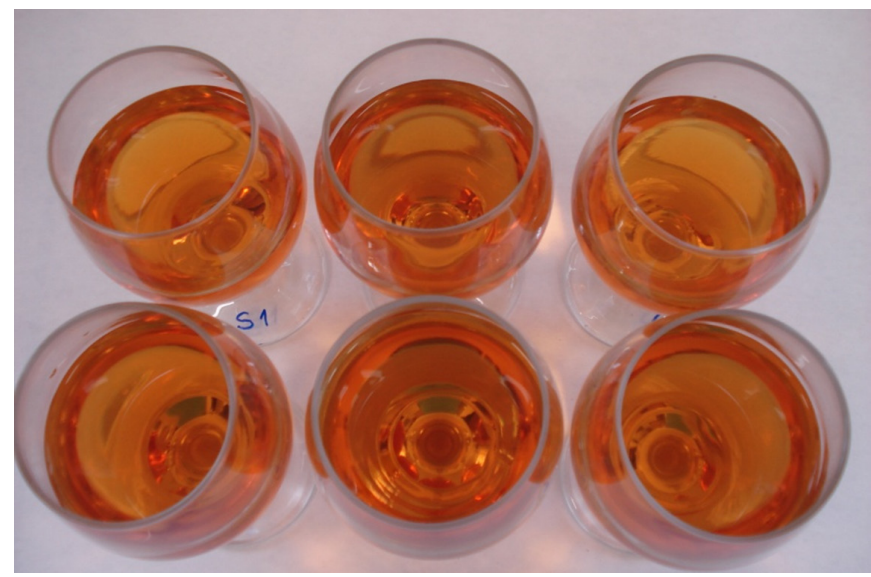

Figura 1. Fermentados de acerola. Na fileira superior, estão os fermentados de suco; na inferior, os fermentados de polpa. Da esquerda para a direita: seco, meio seco e suave.

Tabela 4. Significâncias estatísticas obtidas pelo teste F para as análises sensoriais realizadas nos fermentados de acerola.

\begin{tabular}{lccc}
\multicolumn{1}{c}{ Parâmetros } & $\begin{array}{c}\text { Matéria-prima } \\
\text { (polpa e suco) }\end{array}$ & $\begin{array}{c}\text { Tipo de bebida } \\
\text { (seco, semisseco e suave) }\end{array}$ & $\begin{array}{c}\text { Interação } \\
\text { matéria-prima } \times \text { tipo de bebida }\end{array}$ \\
Aparência & $* *$ & $* *$ & $\mathrm{~ns}$ \\
Odor & $* *$ & $* *$ & $\mathrm{~ns}$ \\
Sabor & $* *$ & $* *$ & $\mathrm{~ns}$ \\
Avaliação global & $* *$ & $\mathrm{~ns}$ \\
\hline
\end{tabular}

${ }^{* *}$ significativo no nível de $1 \%$ de probabilidade $(p<0,01)$. ${ }^{\text {ns }}$ não significativo $(p \geq 0,05)$.

Tabela 5. Comparação de médias dos atributos sensoriais aparência, odor, sabor e avaliação global dos fermentados de acerola.

\begin{tabular}{|c|c|c|c|c|}
\hline \multirow{2}{*}{ Matéria-prima } & \multicolumn{3}{|c|}{ Tipos de bebidas } & \multirow{2}{*}{ Média } \\
\hline & SECO & SEMISSECO & SUAVE & \\
\hline \multicolumn{5}{|c|}{ Aparência } \\
\hline Polpa & $6,98 \pm 1,40$ & $6,96 \pm 1,35$ & $7,06 \pm 1,36$ & $7,00 \pm 1,46^{a}$ \\
\hline Suco & $7,04 \pm 1,59$ & $6,98 \pm 1,50$ & $7,12 \pm 1,30$ & $7,05 \pm 1,46^{a}$ \\
\hline Média & $7,01 \pm 1,49^{a}$ & $6,97 \pm 1,43^{a}$ & $7,09 \pm 1,33^{a}$ & \\
\hline \multicolumn{5}{|c|}{ Odor } \\
\hline Polpa & $6,46 \pm 1,78$ & $6,48 \pm 1,60$ & $6,70 \pm 1,58$ & $6,55 \pm 1,65^{a}$ \\
\hline Suco & $6,26 \pm 1,60$ & $6,54 \pm 1,57$ & $6,94 \pm 1,28$ & $6,58 \pm 1,51^{a}$ \\
\hline Média & $6,36 \pm 1,69^{a}$ & $6,51 \pm 1,57^{a}$ & $6,82 \pm 1,44^{\mathrm{a}}$ & \\
\hline \multicolumn{5}{|c|}{ Sabor } \\
\hline Polpa & $4,88 \pm 2,20$ & $5,54 \pm 1,79$ & $7,24 \pm 1,51$ & $5,89 \pm 2,89^{a}$ \\
\hline Suco & $5,14 \pm 1,94$ & $6,30 \pm 1,80$ & $7,34 \pm 1,67$ & $6,23 \pm 2,00^{a}$ \\
\hline Média & $5,0 \pm 2,07^{c}$ & $5,87 \pm 1,81^{b}$ & $7,29 \pm 1,60^{a}$ & \\
\hline \multicolumn{5}{|c|}{ Avaliação global } \\
\hline Polpa & $5,64 \pm 1,97$ & $6,06 \pm 1,52$ & $7,34 \pm 1,30$ & $6,35 \pm 1,77^{a}$ \\
\hline Suco & $5,94 \pm 1,46$ & $6,36 \pm 1,40$ & $7,4 \pm 1,34$ & $6,57 \pm 1,52^{a}$ \\
\hline Média & $5,79 \pm 1,74^{b}$ & $6,21 \pm 1,46^{b}$ & $7,37 \pm 1,32^{\mathrm{a}}$ & \\
\hline
\end{tabular}

Médias seguidas pela mesma letra minúscula entre colunas e maiúscula entre linhas não diferem significativamente entre si, a $5 \%$ de probabilidade, pelo teste de Tukey. 
$\mathrm{Na}$ avaliação global, os fermentados mais adocicados foram os preferidos pela equipe sensorial, a exemplo do que aconteceu com o atributo sabor.

\section{Conclusões}

Dentro das condições em que os testes experimentais foram conduzidos, podem-se tirar as seguintes conclusões:

- As matérias-primas (suco e polpa) e os tipos de bebidas (seco, semisseco e suave) interferem nos parâmetros físico-químicos e sensoriais dos fermentados de acerola;

- A percepção sensorial dos provadores não foi afetada pelo tipo de matéria-prima (suco e polpa), mas sim pela concentração de açúcar dos fermentados de acerola;

- A equipe sensorial preferiu os fermentados de acerola suaves aos secos.

\section{Agradecimentos}

À FAPESP, pelo auxílio concedido (processo 2008/54302-0). À Associação Agrícola de Junqueirópolis (SP).

\section{Referências}

BELITZ, H. D.; GROSH, W.; SCHIEBERLE, P. Carbohydrates. In: BELITZ, H. D.; GROSH, W.; SCHIEBERLE, P. Food Chemistry. 4th ed. Berlin: Springer, 2009. cap. 4, p. 248-339.

BRASIL. Ministério da Agricultura, Pecuária e Abastecimento. Decreto $n^{\circ} 6.871$, de 04 de junho de 2009. Regulamenta a Lei $n^{\circ} 8.918$, de 14 julho de 1994. Dispõe sobre a padronização, a classificação, o registro, a inspeção, a produção e a fiscalização de bebidas. Diário Oficial da República Federativa do Brasil, Brasília, DF, 05 jun. 2009. Seção 1. Disponível em: <http:// gpex.aduaneiras.com.br/gpex/gpex.dll/infobase/atos/decreto/ decreto6871_09/dec\%2006871_09_01.pdf>. Acesso em: 23 jan. 2010

BRASIL. Ministério da Saúde. Agência Nacional de Vigilância Sanitária. Métodos Físico-químicos para Análise de Alimentos. 4. ed. Brasília: Ministério da Saúde, 2005. 1018 p.

BRASIL. Ministério da Agricultura. Portaria $n^{\circ} 229$, de 25 de outubro de 1988. Normas referentes à complementação dos padrões de identidade e qualidade do vinho e dos derivados da uva e do vinho. Diário Oficial da República Federativa do Brasil, Brasília, DF, 31 out. 1988. Dispónível em: <http://extranet.agricultura.gov.br/sislegisconsulta/servlet/ VisualizarAnexo?id=3602>. Acesso em: 14 ago. 2009.

BEHRENS, J. Análise sensorial de bebidas. In: VENTURINI FILHO, W. G. (Coord.). Indústria de Bebidas: Inovação, Gestão e Produção. São Paulo: Edgard Blucher, 2011. cap. 9 , p. 183-213.
BRUNINI, M. A.; MACEDO, N. B.; COELHO, C. V.; SIQUIERA, G. F. Caracterização física e química de acerolas provenientes de diferentes regiões de cultivo. Revista Brasileira de Fruticultura, Jaboticabal, v. 26, n. 3, p. 486-489, 2004.

CAETANO, P. K.; DAIUTO, E. R.; VIEITES, R. L. Característica físico-química e sensorial de geleia elaborada com polpa e suco de acerola. Brazilian Journal Food Technology, Campinas, v. 15, n. 3, p. 191-197, 2012. http://dx. doi.org/10.1590/S198167232012005000011

CATALUÑA, E. As Uvas e os Vinhos. 3. ed. São Paulo: Globo, 1991. 215 p.

COPERSUCAR. Métodos analíticos. In: COPERSUCAR. Manual de Controle Químico da Fabricação de Açúcar. Piracicaba: Centro de Tecnologia Copersucar, 2001. cap. 4, p. 1-51.

EVANGELISTA, A. F.; ALMEIDA. S.; SANTANA, J. C.; SOUZA, R. R. Avaliação RSM de fatores que influenciam na produção de vinho de acerola. Brazilian Journal of Food Technology, Campinas, v. 10, p. 8-13, 2005. Edição especial $5^{\circ}$ SIPAL.

HASHIZUME, T. Tecnologia do vinho. In: AQUARONE, E.; BORZANI, W.; SCHMIDELL, W.; LIMA, U. A. (Coords.). Biotecnologia Industrial: Biotecnologia na Produção de Alimentos. São Paulo: Edgard Blucher, 2001. cap. 2, p. 21-68.

MANICA, I.; ICUMA, I. M.; FIORAVANÇO, J. C.; PAIVA, J. R.; PAIVA, M. C.; JUNQUEIRA, N. T. V. Acerola: Tecnologia de Produção, Pós-colheita, Congelamento, Exportação, Mercados. Porto Alegre: Cinco Continentes, 2003. 397 p.

OLIVEIRA, D. T. Impactos dos Itens da Especificação de Qualidade do Açúcar na Indústria Alimentícia. Piracicaba: COPERSUCAR, 2006. 1 CD-ROM.

RIBEIRO, E. P.; SERAVALLI, E. A. G. Química de Alimentos. São Paulo: Blucher, 2004. 184 p.

RIZZON, L. A.; MIELE, A. Extrato seco total de vinhos brasileiros: comparação de métodos analíticos. Ciência Rural, Santa Maria, v. 26, n. 2, p. 297-300, 1996.

SANTOS, S. C. Elaboração e análise sensorial do fermentado de acerola (Malpighia punicifolia L.). Brazilian Journal of Food Technology, Campinas, v. 10, p. 47-50, 2005. Edição especial $5^{\circ}$ SIPAL.

SILVA, F. A. S.; AZEVEDO, C. A. V. Principal components analysis in the software assistat-statistical attendance. In: WORLD CONGRESS ON COMPUTERS IN AGRICULTURE, 7., 2009, Reno. Proceedings... St. Joseph: American Society of Agricultural and Biological Engineers, 2009. Disponível em: <http://elibrary.asabe.org/azdez.asp?JID=1\&AID=29066\&CID =wcon2009\&T=2>. Acesso em: 7 nov. 2012.

VIEIRA, S. Análise de Variância: (Anova). São Paulo: Atlas, 2006. 204 p. 